\title{
Lindenwood College
}

From the SelectedWorks of John A. Henschke EdD

2014

\section{Andragogical Curriculum for Equipping Successful Facilitators of Andragogy in Numerous Contexts}

John A. Henschke, EdD 


\title{
Chapter 8 Andragogical Curriculum for Equipping Successful Facilitators of Andragogy in Numerous Contexts
}

\author{
John A. Henschke \\ Lindenwood University, USA
}

\begin{abstract}
This chapter addresses a curriculum definition, especially as it relates to preparing teachers to be successful in working with adult learners. The main thrust is to clearly articulate some of the major elements needed to help the art and science of helping adults learn the ideas and practices of that process and be as consistent/congruent as feasible. Reciprocity among empathy, trust, and sensitivity are considered to be crucial in the teaching and learning exchange. Competence and experience in andragogy is important even to the extent of selecting and using various techniques and methods in the learning experience, whether used with learners in higher-order thinking or used with lower-level learners. Techniques the author has found helpful are: mixing a lecture with discussion of questions raised by learners in response to content of the lecture; encouraging and giving learners opportunity to take more responsibility for their learning, thus becoming more self-directed; varying one's approach for accommodating different learning styles each learner possesses; looking at a perspective of learning in various areas/pillars of life - being, knowing, doing, living together, changing, and developing sustainability. A true story is provided illustrating a principle of andragogy-doing in practice the same thing one believes and says.
\end{abstract}

\section{INTRODUCTION}

Curriculum is a broad and interesting topic in and of itself. Ask any group of people and it is quite certain that each would attach her/his own meaning to the word, without including a specific definition. However, to carry it beyond just the single word and connect it with other words and phrases, it takes on very different connotations. In this situation, curriculum is being connected with the andragogy (the art and science of facilitating or helping adults in accomplishing their learning) while focusing on helping equip the facilitator of andragogy to be successful in numerous contexts.

DOI: 10.4018/978-1-4666-5872-1.ch008 


\section{A Definition of Curriculum}

Curriculum in general is considered to be (Devlin, 1939 , p. 414) applied particularly to the course of study in a university, college, or school. Jarvis (1990, p. 89) in relating the curriculum to adult education finds denial of adult education having a curriculum as well as identification of curriculum with the term program. He does suggest that curriculum tends to mean the entire range of learning experiences provided by an educational institution, one of the numerous contexts where adult education may be conducted.

A much clearer articulation of the particulars which "learning experiences" encompass is given by Knoll (1989, as cited in Titmus, p. 29) using the German Education Council definition that curriculum means the organized arrangement of learning processes and content with regard to certain aims and objectives which include techniques, behavior or type and degree of certain skills and aptitudes, or of knowledge. This could imply and prompt such questions as: which knowledge, understanding, aptitudes, skills, interests, attitude, value and behavior pattern is this "learner-who is an educator of adults (or more accurately, andragogue) in preparation" to acquire? With which subject matter and content is this "learner" to be confronted? What is the "learner" to learn? When and where is this "learner" to learn? How are this "learner's needs" to be determined? By which learning steps and techniques, in which manner, with the aid of which materials is this "learner" to learn? How is the attainment of the aims and objectives by this "learner" to be determined? It could be assumed that to answer these questions will necessitate knowing various theories and schools of thought which will inform the selection of the very best practices or learning/teaching techniques which the andragogical educator of adults has at his/her command and level of competency.

Boone (1985) presents a definition of programming or curriculum in adult education as follows:
A comprehensive, systematic, and proactive process encompassing the total planned, collaborative efforts of the adult education organization, the adult educator in the roles of change agent and programmer, representative of the learners, and the learners themselves in a purposive manner and designed to facilitate desirable changes in the behavior of learners and the environment or system in which they live. (p. 41)

Boone also gives an instructional design conceptual program/curriculum model which includes three major parts: Planning, Design \& Implementation, Evaluation \& Accountability. Planning encompasses the organization and its renewal process, and linking the organization to its publics. Design \& Implementation takes in the instructional design of the planned program, and implementing the planned program. Evaluation and Accountability helps determine and measure program inputs and outputs as well as renewal processes.

Although these above expressions and the questions relating to the scope of curriculum are clear, they are somewhat general. Furthermore, for the focus to be on andragogy and not education or adult education in general, there are some specific things that need to be considered to make a curriculum consistent with andragogy, so that the preparing/equipping of the andragogue will be congruent with the principles, theories, practices and underlying foundation of andragogy; thus, approximating as nearly as possible, the preparation of person(s) who will enact and fulfill the role of an andragogical facilitator successfully. Knowles (1970, 1980), however, provides six assumptions and eight process elements of andragogy that help articulate curriculum, or program planning, or steps for instructional design. This will be addressed in the next section. 


\section{Theoretical Framework}

The theoretical framework for curriculum that focuses on an andragogical curriculum is what has become known as a traditional concept described and moved forward by Malcolm Knowles. There are many perspectives that are descriptive of the history and philosophy of andragogy throughout the world (Henschke, 2013). Nonetheless, andragogy has become known from a practical point of view as the art and science of helping adults learn, or the art and science of helping facilitate the learning of adults. For a basic framework on andragogy regarding curriculum, the six assumptions and eight processes as articulated by Knowles (1970) and Henschke (2009, 2011a, 2011b, 2011c) are among the clearestexpressions of andragogical curriculum. An adaptation of this is presented in a capsule form first. Then, these will be fleshed out a bit with extra narrative.

\section{Assumptions about Adult} Learners in an Andragogical Curriculum Model of Learning

1. Adult learners need to know a reason that makes sense to her/him for learning something.

2. Adult learners are increasingly self-directing.

3. The Role of the adult learner's experience becomes a rich resource for learning by self and others.

4. Readiness to learn in the adult develops from life tasks and problems.

5. Orientation to learning for the adult is for immediate application.

6. Motivation of the adult learner is increasingly by internal incentives and curiosity.

Process Elements of an Andragogical Curriculum Model of Learning
1. Preparing adult learners for the program is for them to gain insight and understanding for what is to come.

2. Setting the Learning Climate is for helping adult learners become comfortable, relaxed, trusting, mutually respectful, informal, warm, collaborative, supportive, open, authentic, human, pleasureable and fun.

3. Planning the Learning Experience is to be mutually done by the learners and facilitators.

4. Diagnosis of the Learner's Needs is assessed mutually by learners and facilitators.

5. Setting the Learning Objectives are mutually negotiated by learners and facilitators.

6. Designing the Learning Plans is through learning contracts, learning projects, and sequenced by readiness.

7. Learning Activities are conducted through inquiry projects, independent study, and experiential techniques.

8. Evaluation of the Learning is by learnercollected evidence validated by peers, facilitators, and experts.

\section{Assumptions of Andragogy}

There are six assumptions of andragogy that may be called the cardinal principles which comprise andragogy's theory and these undergird an andragogical curriculum. They are as follows.

The Need to Know: Adults have a need to know a reason that makes sense to them, as to why they should learn some particular thing - why they need to learn the subject matter the teacher has to teach them.

The Learner's Self-Concept: As adults, we have a deep psychological need to be self-directing - to be perceived by others and treated by others as able to take responsibility for ourselves.

The Role of Experience: Adults enter into an educational activity with a greater volume and a 
different quality of experience than youths. The greater volume is obvious - the longer we live, the more experience we accumulate. The difference in quality of experience arises from the different roles adults and young people perform.

Readiness to Learn: Adults become ready to learn when they experience a need to know or be able to do something to perform more effectively in some aspect of their lives. Among the chief sources of readiness are the developmental tasks associated with moving from one stage of development to another. Any change-marriage, the birth of children, the loss of a job, divorce, the death of a friend or relative, or a change of residence - can trigger a readiness to learn.

Orientation to Learning: Because adults are motivated to learn after they experience a need, they enter an educational activity with a life-, task-, or problem-centered orientation to learning.

Motivation: Although the andragogical model acknowledges that adults will respond to some external motivators-for example, a chance for promotion, a change of jobs, or a change in technology - it proposes that the more potent motivators are internal-such benefits as self-esteem, recognition by peers, better quality of life, greater self-confidence, self-actualization, and so on.

\section{Process Elements of Andragogy}

There are eight process elements that help to flesh-out the way that an andragogical curriculum may possibly (in all probability, needs to) be enacted. These are first expressed as a statement. Then each is followed by a question to help one decide the procedure[s], methods and techniques that will help learners become actively involved in carrying out the application of andragogy to any subject matter, and meet the expectation of the participants. They are as follows.

Preparing the Learners for the Andragogical Program/Course: A most common introduction to the participants is sharing the purpose, objectives, meeting time and place, potential benefits, the participatory nature of the learning design so the adult learners develop some realistic expectations about how they will be involved, and things to think about such as what special needs, questions, topics, and problems they hope will be dealt with.

The first question an andragogue asks in constructing a process design, therefore, is "What procedures should I use to help prepare the adult learners to become actively involved in this course and to meet their expectations?"

Setting the Climate: A climate conducive to andragogical learning is a prerequisite for effective learning. Two aspects of climate are important: physical and psychological.

Physical Climate: The typical classroom setup, with chairs in rows and a lectern in front, is probably the one least conducive to learning that the fertile human brain could invent. It announces to anyone entering the room that the name of the game here is one-way transmission - the proper role for the students is to sit and listen to the professor. The effective educator of adults makes a point of getting to the classroom well before the learners arrive. If it is set up like a traditional classroom, consider moving the lectern to a corner and rearrange the chairs in one large circle or several small circles. If tables are available, place five or six at a table. A bright and cheerful classroom is a must.

Psychological Climate: Important as physical climate is, psychological climate is even more important. The following characteristics create a psychological climate conducive to andragogical learning:

- A Climate of Mutual Respect: Adults are more open to learning when they feel respected. If they feel that they are being talked down to, ignored, or regarded as incapable, or that their experience is not being valued, then their energy is spent dealing with these feelings at the expense of learning.

- A Climate of Collaboration: Because of their earlier school experiences where competition for grades and the professor's/ teacher's favor was the norm, adults tend 
to enter into any educational activity with rivalry toward fellow learners. Because peers are often the richest resources for learning, this competitiveness makes these resources inaccessible. There are climatesetting exercises that can be used to open courses which put the learners into a sharing relationship from the beginning for this reason.

- A Climate of Mutual Trust: People learn more from those they trust than from those they aren't sure they can trust. Facilitators of learning will do well to present themselves as a human being rather than as an authority figure, to trust the people they work with and to gain their trust.

- A Climate of Support: People learn better when they feel supported rather than judged or threatened. Teachers of adult learners try to convey their desire to be supportive by demonstrating their acceptance of them with an unqualified positive regard, empathizing with their problems or worries, and defining their role as that of helper.

- A Climate of Openness and Authenticity: When people feel free to say what they really think and feel, they are more willing to examine new ideas and risk new behaviors than when they feel defensive. If professors demonstrate openness and authenticity in their own behavior, this will be a model that the adult learner will want to adopt.

- A Climate of Pleasure/Fun: Learning should be one of the most pleasant and gratifying experiences in life; it is, after all, the way people can achieve their full potential. Learning should be an adventure, spiced with the excitement of discovery. It should be fun. Dullness is the unacceptable part of the adult learners' previous educational experience, and the professor will improve the learning climate by making a lot of use of spontaneous [not canned] humor.
- A Climate of Humanness: Learning is a very human activity. The more people feel they are being treated as human beings, the more they are likely to learn. This means providing for human comfort-good lighting and ventilation, comfortable chairs, availability of refreshments, frequent breaks, and the like. It also means providing a caring, accepting, respecting, and helping social atmosphere.

The second question an andragogue asks in constructing a process design is "What procedures should I use with this particular group to bring these learning climatic conditions into being?"

Involving Learners in Mutual Planning: The andragogical process model emphasizes learners sharing the responsibility for planning learning activities with the facilitator. There is a basic law of human nature at work here: People tend to feel committed to any decision in proportion to the extent to which they have participated in making it. The reverse is even more true: People tend to feel uncommitted to the extent they feel that the decision or activity is being imposed on them without their having a chance to influence it.

The third question the andragogue answers in developing a process model, therefore, is "What procedures will I use to involve the learners in planning?"

Diagnosing their own Learning Needs: At the very simplest level, learners can share in small groups what they perceive their needs and interests to be regarding the acquisition of knowledge, understanding, skill, attitude, value and interest in a given content area of the course. One member of each group can volunteer to summarize the results of this discussion. This way, the learners will at least enter into the learning experience with some awareness of what they would like to get out of it. A learning need is not a need unless perceived so by the learner. It is possible to induce a deeper and more specific level of awareness by having learners engage in some of the new body of technology being developed for facilitating this 
process, with emphasis on such self-diagnostic procedures as in simulation exercises, assessment techniques, competency-based rating scales, and videotape feedback.

So the fourth set of questions the andragogue asks in constructing a process design is "What procedures will I use in helping the participants diagnose their own learning needs?"

Translating the Learning Needs into Objectives: Having diagnosed their learning needs, participants now face the task of translating them into learning objectives-positive statements of directions of growth. Some kinds of learning [such as identifying criteria for various steps in accomplishing a particular task] lend themselves to objectives stated as terminal behaviors that can be observed and measured. Others [such as decisionmaking ability] are so complex that they are better stated in terms of direction of improvement.

The fifth question the andragogue asks is "What procedures can I use for helping involve the adult learner in translating their learning needs into andragogical learning objectives?"

Designing a Pattern of Learning Experiences: Having formulated the learning objectives, the professor and the adult learner then have the mutual task of designing a plan for achieving them. This plan will include identifying the resources most relevant to each objective and the most effective strategies for utilizing these resources. Such a plan is likely to include a mix of total group experiences [including input by the professor], and subgroup [learning-teaching team] experiences, and individual learning projects. A key criterion for assessing the excellence of such a design is, "how deeply are the learners involved in the mutual process of designing a pattern of learning experiences?
So the sixth question the andragogue asks is "What procedures can I use for involving the learners with me in designing a pattern of andragogical learning experiences?"

Helping Adult Learners Manage and Carry Out Their Learning Plans: Learning contracts are a most effective way to help learners structure and conduct their learning. Students [adult learners] contract with the professor to meet the requirements of the university courses in which they are enrolled. [Incidentally, even though there may be a number of nonnegotiable requirements in university courses, the means by which learners accomplish the required objectives can be highly individualized.] Students going out on a field experience, such as a practicum or internship, will contract with the professor and the field supervisor. Contracts may also be specify how the learner is going to continue to learn on their own. Learning contracts are also used for continuing personal and professional development.

The seventh question that andragogue asks is "What procedures can I use to make certain the learners are full engaged and involved with me in managing and carrying out their learning plan?"

Evaluating the Extent to Which the Learners Have Achieved their Objectives: In many situations institutional policies require some sort of "objective" (quantitative) measure of learning outcomes. However, the recent trend in evaluation research has been to place increasing emphasis on "subjective" (qualitative) evaluation-finding out what is really happening inside the learners and how differently they are performing in life. In any case, the andragogical model requires that the learners be actively involved in the process of evaluating their learning outcomes.

The eighth question, therefore, that the andragogue asks is "What procedures can I use to involve the learners responsibly in evaluating the 
accomplishment of their learning objectives and meeting the course requirements?" By answering these eight questions, the facilitator of adult learning emerges with an andragogical process design - a set of procedures for facilitating the acquisition of the course content by the adult learner. The answers to these questions require thought and contemplation about how the choices one makes will affect the outcome of the curriculum, no matter what the subject matter. It is the process of how the facilitator engages with the participants in and throughout the learning process that matters the most.

\section{Main Thrust}

The main thrust on andragogical curricula that is being moved forward in this article is for providing illustrations (based on sound theory and research) of how the author and some others have worked vigorously on this concept and making the theory and process as consistent as is possible.

\section{Modeling and Consistency in Andragogical Curriculum}

One way of depicting andragogical curriculum is to focus on the idea of modeling our theory through exemplifying our practice so that it will be consistent with what we say we believe about how to prepare andragogues to become successful. The idea is to do the very thing that is said, rather than saying one thing and doing another (Henschke, 1998).

When one says "adult educators," she/he may indicate a broader range of individuals than one would think upon first consideration. However, the more specific term may be 'andragogues.' If andragogues are people who "help adults learn," then their ranks could include: (1) leaders in voluntary associations: (2) executives, training officers, supervisors and foremen in corporations: (3) teachers, administrators and group leaders in various educational institutions; and (4) program directors, writers and editors in educational areas of mass media; as well as (5) professional adult educators who have been prepared specifically for this vocation and make it their permanent career. However, if they are to effectively facilitate adults in their learning, these andragogues need to be competent in an aspect of andragogy that is so crucial - modeling.

Henschke observed, in more than 40 years of preparing andragogues to help adults learn, that the validity of teaching ultimately derives from a single element: modeling. Modeling, according to the dictionary means providing an example worthy of imitation, a standard by which a thing can be measured. For an andragogue, that means exemplifying the lessons being taught. It means walking what one talks, not "Do as I say, not as I do."

If one looks to ancient times, thefindings present Moses as a model prophet and law giver, Confucius as a model thinker, Abraham as a model of faith, Socrates as a model questioner, Jesus Christ as a model of forgiving love, and Tullius Cicero as a model of eloquent oratory. Each ones personal influence is still pervasive in the present time.

In reviewing the history of the United States of America, one discovers George Washington to be a model of prudence, integrity and patriotism; Thomas Jefferson to be a model of learnedness; Teddy Roosevelt to be a model of courage, and Abraham Lincoln to be a model of honesty and justice. And it can be seen how their modeling of these virtues has helped shape the present world —as clearly as their images carved into Mt. Rushmore.

To emphasize all this in very personal language, as andragogues, we are models. Students learn more from our actions than our words. They want to see if our actions match our words. With this in mind, if we believe that adults learn in a certain way, then it follows that we take it upon 
ourselves to model the conduct and attitude that demonstrate and support what we're trying to exemplify in helping facilitate their learning.

A guiding principle and statement in the andragogy curriculum at Lindenwood University, School of Education is: "If I am not modeling what I am teaching, I am teaching something else." One could also say: "if I am modeling what I am teaching, then I am teaching what I am modeling." This andragogical principle is much like that of the Zaddik Rabbi, who paraphrased says the personality of the andragogue takes the place of the facilitation of learning — she or he is the facilitation of learning. For us whose task is to help facilitate the learning of adults, it means risking being ourselves, trusting our feelings and acting on them, thereby engaging a like commitment from our learners.

\section{An Outline of Modeling}

There are certain ingredients that go into the making of a model. Understanding each of these ingredients can help us in our andragogical practice of modeling in the preparation of other andragogues - being facilitators of learning.

Andragogy: One ingredient is the theory of andragogy---the art and science of helping facilitate the learning of adults. Its primary principle is the desire, potential and ability for self-directedness on the part of the learner. Other principles include: perceiving the learner's experience as a resource for learning, seeing developmental tasks of social roles as crucial in activating the need and readiness for learning, learners need a situation-centered or problem-centered orientation to learning, understanding that motivation of adult learners is very internal rather than merely external, and learners need a valid reason why they need to learn something to appreciate its importance.

Henschke experienced these principles of andragogy in his studies at Boston University with Malcolm Knowles who exemplified the theory in the United States and has now passed the torch of leadership (modeling) in andragogy to the next generation. He heard people say that Malcolm provided a set of injunctions from which we will gain benefit if we follow them; and that, if a teacher has some notion of what Knowles is talking about, both learner and teacher will greatly benefit in a learning situation.

Henschke has implemented these principles of andragogy in his own facilitation of adult education and in working with masters and doctoral students for more than three decades. He also has worked in andragogy within 19 countries; and, has engaged learners in andragogical processes from 96 countries in the broader community around the globe. Teaching the way he was taught has worked well for him, as he has seen many adult educators blossom and flourish into effective andragogues in their research and practice.

Eduard Lindeman said that andragogy is the true method by which adults keep themselves intelligent about the modern world, and that its use would make a qualitative difference in the life of our time. He further asserted the practical nature of andragogy: theory becomes fact and words become responsible acts and accountable deeds.

Attitude: A second ingredient is attitude. Someone said that if andragogy is used only as a method for conducting learning activities, it may become mechanical and lose its dynamism. Andragogy is more than mere method; it is an attitude of mind and heart, and it becomes a transforming power and positive influence in modeling the preparation of adult educators. An attitude of caring for the learner as a valuable, unique person and of helping the learner to accomplish his or her educational goals, is essential for an adult educator; it is like the warp and woof of an exquisitely beautiful cloth weaving,

Congruence: A third ingredient is congruence. In mathematics if two numbers give the same remainder when divided by a given value they are said to be congruent, In adult education, if we apply our andragogical principles consistently, we will achieve congruence with learners in the form of 
a mutual agreement of voluntary conformity. For that to happen, there must be congruence between theory and practice, even though one may think that is not very scholarly.

Congruence of theory and practice needs to be like two geometric figures superimposed on one another or like an architectural plan for a building and the actual building.

Reciprocity of Empathy, Trust, and Sensitivity: The fourth is a combination of ingredients - the reciprocity of empathy, trust, and sensitivity. To be effective, an andragogue needs to combine the reciprocity of empathy, trust, and sensitivity in concert with the ability and potential of learners for the same (who may be emerging andragogues) to understand the learning process and interact with facilitators effectively in making the right choices. This reciprocity takes the form of the facilitator initiating and maintaining the combination of three elements that follow: Empathy, trust, and sensitivity, Insensitivity may get in the way and block the modeling process.

\section{Empathy: The Andragogue}

- Feels fully prepared to teach.

- Notices and acknowledges to learners positive changes in them.

- Balances her/his efforts between learner content acquisition and motivation.

- Expresses appreciation to learners who actively participate.

- $\quad$ Promotes positive self-esteem in learners.

Trust: The Andragogue

- $\quad$ Purposefully communicating to learners that they are each uniquely important;

- Believing learners know what their goals, dreams and realities are like ;

- Expressing confidence that learners will develop the skills they need;

- $\quad$ Prizing the learners to learn what is needed;
- Feeling learners' need to be aware of and communicate their thoughts and feelings;

- Enabling learners to evaluate their own progress in learning;

- Hearing learners indicate what their learning needs are;

- $\quad$ Engaging learners in clarifying their own aspirations;

- Developing a supportive relationship with learners;

- Experiencing unconditional positive regard for learners; and,

- $\quad$ Respecting the dignity and integrity of learners.

Insensitivity: The Insensitive Educator (without Reciprocity, Leans Much More to the Side of Insensitivity)

- Has difficulty understanding learner's point of view.

- Has difficulty getting her/his point across to learners.

- Feels impatient with learner's progress.

- Experiences frustration with learner apathy.

- Have difficulty with the amount of time learners need to grasp various concepts.

- Gets bored with the many questions learners ask.

- $\quad$ Feels irritation at learner inattentiveness in the learning setting.

Sensitivity: The Andragogue (with Reciprocity, an Andragogue Leans Much More to the Side of Sensitivity)

- Makes certain to understand the learner's point of view.

- Takes pains and time to get her/his point across to learners.

- Exercises patience in helping all learner's progress. 
- Overcomes any frustration with learner apathy.

- Will use whatever time learners need to grasp various concepts.

- Thoroughly allows learners to ask all questions they need addressed.

- Resists in her/himself any irritation at learner inattentiveness in the learning setting.

\section{Modified Instructional Perspectives Inventory (MIPI) Validated Three Times}

Henschke (1989) developed the Modified Instructional Perspectives Inventory (MIPI) (Henschke, 1989), which includes seven factors: [1] Teacher Empathy with Learners; [2] Teacher Trust of Learners; [3] Planning and Delivery of Instruction; [4] Accommodating Learner Uniqueness; [5] Teacher Insensitivity to Learners; [6] LearnerCentered Learning Processes (Experience-Based Learning Techniques); [7] Teacher-Centered Learning Processes. From the outset, factor \#2 (Teacher Trust of Learners has been the strongest factor of the seven.
The original IPI was changed by Stanton (2005) from a four-point Likert Scale to a five-point Likert Scale, becoming the Modified Instructional Perspectives Inventor (MIPI). The MIPI was validated numerous times and statistics are presented below on three of them - Stanton (2005), Moehl (2011), and Vatcharasirisook (2011). Stanton and Moehl worked with the wording of the factors such as "Teacher Trust of Learners." This wording was focused on groups that were in an educational setting. Vatcharasirisook worked with the wording of the factors such as "Supervisor Trust of Subordinates." The reason for the change of wording on the last one was that it was focused on groups that were in a work setting. So to replace the word teacher, the word supervisor was used. To replace the word learner, the word subordinate was used. Nevertheless, the same validation technique was used in each instance. The results show that it was equally valid to use the different terminology to designate the various roles and situations people were fulfilling.

Figure 1 shows Cronback's alpha coefficient calculations for the three dissertations that validated the instrument.

Figure 1. MIPI validity calculations

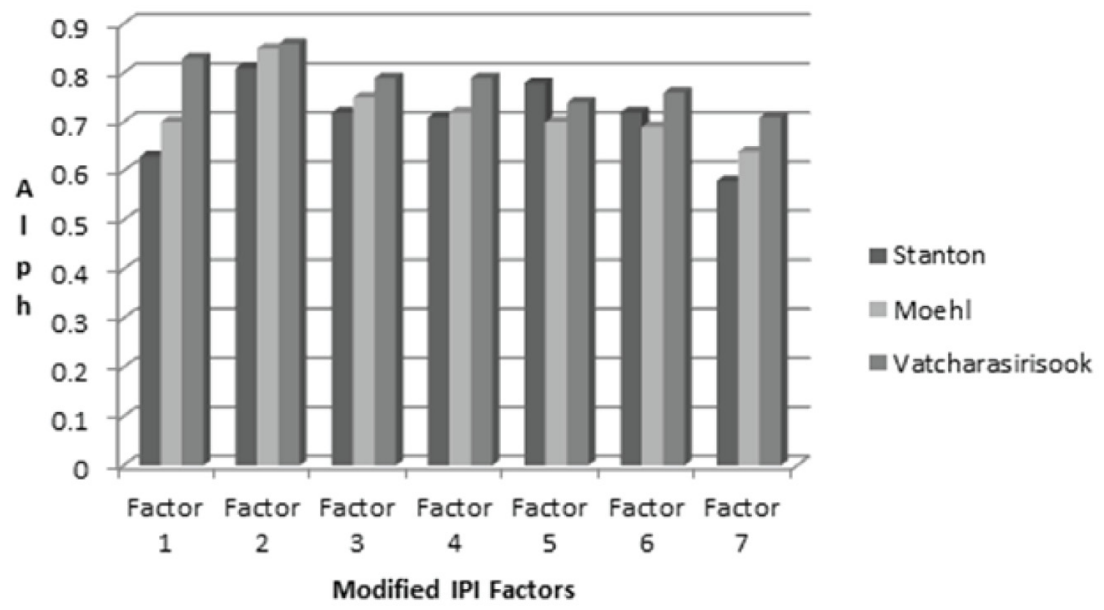


Modified Instructional Perspective Inventory factors follow:

Factor 1: Teacher/supervisor empathy with learner/subordinate.

Factor 2: Teacher/supervisor trust of learner/ subordinate.

Factor 3: Planning and delivery of instruction.

Factor 4: Accommodating learner/subordinate uniqueness.

Factor 5: Teacher/supervisor insensitivity toward learner/subordinate.

Factor 6: Learner/subordinate-centered processes.

Factor 7: Teacher/supervisor-centered processes.

If any reader wishes to have a copy of the MIPI and scoring scale, please mail John A. Henschke at the following address: jhenschke@ lindenwood.edu

\section{Dealing with Possible Conflicts in Modeling}

Although each of the seven factors contributes to the overall validity and reliability of the Inventory (it has been used in 17 Doctoral Dissertations [Henschke, 2011a; Lubin, 2013] and been validated and revalidated four times since its inception in 1989 [Vatcharasirisook, 2011; Henschke, 1989]) three factors are the most important toward its central contribution to andragogical Teachers and Learners in the classroom (in addition to Supervisors and Supervisees in the workplace) related to the Field of Adult and Higher Education. The three most important factors are: 1. Teacher Empathy with Learners; 2. Teacher Trust of Learners; and, 5. Teacher Insensitivity toward Learners. The andragogue needs to initiate, establish, and maintain reciprocation with learners in empathy with learning, trust of learners, and sensitivity toward learners. If he or she effectively models the principles of andragogy, learners have a golden opportunity to become great andragogues them- selves. If reciprocating with learners in empathy, trust, and sensitivity is exemplified, the learners may learn something, which otherwise, they would have learned less well, more slowly, or not at all. A lack in the combination of empathy, trust, and sensitivity, seriously hampers the learning process.

If andragogues and learners would rate each one of the items very high and fairly close to each other regarding empathy and trust, it would become quite clear that there would be an excellent empathy and trusting relationship between the two based on what these sixteen items express. In addition, reciprocity becomes part of the nature of the relationship, and obviously the following expressions and descriptions of a reciprocal relationship characterize the situation -- interrelatedness, mutual assistance, give and take, aiding and abetting, mutuality, interplay, cooperation, collaboration. The factors of empathy and trust contribute toward learner satisfaction with the learning situation and the subordinate satisfaction with the job (Vatcharasirisook, 2011). The combination of these two factors - empathy and trust - not only leads to learning situation satisfaction and subordinate job satisfaction, but, in turn, these in combination secondarily lead to the learner and subordinate wanting to stay in the learning situation or want to stay employed in the organization where they are working (Vatcharasirisook, 2011). When one considers the amount of time and money it takes an organization to orient a learner or subordinate to the culture, values and practices which make up the atmosphere or climate of that institution, it is important that the atmosphere and climate be conducive to encouraging personnel to remain and be retained within. When this happens, these personnel may possibly contribute productively to the purpose and mission of the institution. There are other considerations to be observed relating to retention of personnel within an institution. This is related to the seven items comprising the sensitivity/insensitivity factor.

This is one of the most crucial aspects of implementing the issue of learning situations and 
job satisfaction aspects of trust, empathy, reciprocation, and sensitivity between andragogues and learners. All may be well in these regards and indications may be leaning toward 'smoothsailing' between them, especially when trust and empathy are harmonizing. However, when it comes to the extent of sensitivity/insensitivity between andragogues or supervisors and learners or subordinates, if the leanings of either or both are toward sensitivity, harmony may easily be maintained. Nonetheless, if the leanings of either or both are toward insensitivity, the harmony generated by high trust and empathy may almost certainly be lessened at best, scuttled or destroyed at worst, with the accompanying result of the learners/ subordinates acting on their desire to get out of that learning situation or workplace (Henschke, 2011c; Vatcharasirisook, 2011).

It may seem strange that it works that way. Moreover, if only one item from Factor \# 5 is amiss, one may think that it will not matter or influence the learning situation or the workplace sufficiently to have a negative impact. Notwithstanding, a number of years ago (circa, 1978), Henschke heard Fran Tarkenton, long time quarterback of the Minnesota Vikings and Entreprenuer of a professional development motivation corporation, make the statement that it takes five positive statements to off-set the influence of one negative statement, so also in the case of factor \# 5 with insensitive items and influencing a person to leave a corporation. Along the same line, when the South African Government was being helped to rid the country of Apartheid, there were nine major elements that the consultants considered as necessary to help them accomplish that task (McLagan \& Nels, 1995). Their research substantiated that all nine elements held together as a unified major influence. If all elements except one were upheld, the one element not upheld contributed to destroying the unity and the total effort crumbling and resulting in no value to the country seeking to eliminate Apartheid. In addition, Lazersfeld and Katz $(1955,2006)$ found in their original research, which is still valid a half-century later, that it is the relationship that teaches - the closer the relationship is, the more learning will occur; the more distant the relationship is, the less reciprocity, interrelatedness, mutual assistance, give and take, aiding and abetting, mutuality, interplay, cooperation, and collaboration; consequently, the less learning will take place.

Thus, the same is probably true relating to the sensitivity/insensitivity factor between andragogues and learners. It is not just one of the seven items in sensitivity/insensitivity that may be acceptable to overlook, but it is that if one of the seven items in this factor is considered unimportant, all of the eleven items of trust, combined with all of the five items of empathy will be of no avail in building the solid foundation of learning that will flourish with trust, reciprocity and relationships. All seven items in this factor hold together as a unified influence. If one item is missing, the influence of this factor is nullified. Or, from the opposite point of view, if one item of insensitivity is strongly present, it nullifies what could be the positive influence of the other six items of this factor as well as nullifying the positive effect in the relationship of the factors of trust and empathy. This means that concentrated attention must be given to greatly reduce or eliminate entirely each item of our practice that relates to insensitivity on the part of teachers or supervisors toward learners or subordinates. This is a critical distinction to make and needs to be dealt with as being of utmost importance.

\section{Building Blocks for Adult Learning in Andragogy}

Henschke likes to encourage emerging andragogues to focus on five building blocks: (1) beliefs and notions about adults as learners; (2) perceptions concerning the qualities of effective andragogues/facilitators; (3) phases and sequences of learning process (theory of how learning takes place); 4) teaching tips and learning techniques; 
and, (5) implementation of the prepared plan. Modeling - andragogy: attitude, congruence and reciprocation of empathy, trust, increasing sensitivity and decreasing insensitivity — while using these building blocks, helps to move the preparation of adult full circle from concept to reality.

A person may wish to incorporate other ingredients as part of modeling the preparation of andragogical adult educators-based on your experience, someone else's experience, or an interesting theory you've heard. In any case Henschke's observations indicate to him that the aforementioned ingredients - andragogy, attitude, congruence, and reciprocation of empathy, trust and sensitivity, along with the minimizing or eliminating of insensitivity-are basic considerations. He has found that it is possible to be himself and to be congruent in a university setting without sacrificing academic quality or rigor. He found this to be true in varying time-frames within non-academic settings as well, meaning that all people who "help adults learn" — not just professional andragogues - can use the modeling principle in the preparation of adult educators to become successful andragogues. Modeling is not all there is to andragogy, but it is a substantial part. Other elements and implementing our beliefs about how we may support adult learners, as described and articulated in the assumptions about adult learners as well as the process element of conducting learning experiences, are also very crucial in becoming successful andragogues who will contribute great benefit to the constituencies and larger society that are being served by our exercising and exemplifying our craft. the author agrees with an adult educator friend of his who said that if we carry forward the andragogy we are talking about, we are going to get it right yet, and others along with us will be abundantly enriched.

\section{Perceptions Concerning the Additional Qualities of Effective Andragogical Teachers}

Lest Henschke gives the impression that "modeling' is all that is necessary for becoming a successful andragogue, $\mathrm{He}$ is adding the following comments and suggestions. This part of the process of self-diagnostic, as well as modeling being subject to self-diagnostic.

1. Interest in the Learners and the Subject Being Studied: Learners are quick at determining how interested teachers are in them and the subject being taught. One is not to be present to the exclusion of the other. Effective, successful andragogues demonstrate sincere concern and interest in their learners and well-being.

2. Ability to Communicate Well: Communication is the act of helping others learn concepts, skills and attitudes. Andragogues communicate by speaking, listening and writing. Communication includes presenting material in a clear and straightforward manner using language and written materials geared to learners' comprehension levels. Since learning is an active process, communication methods used must actively engage learners.

3. Good Knowledge of theSubject: Successful andragogues have a thorough and comprehensive knowledge of the subject they are helping the learners learn. The expectations of the learners is that the teacher will be able to respond to their questions and help them develop their areas of interest. However, when challenged by a question, the andragogue needs to admit to not knowing the answer as well as expressing willingness to work with the learner to find the answer. 
4. Prepared to Facilitate Learning of the Lesson: Good facilitation and good planning go hand in hand. Planning requires an investment of time. It should be a joint virtue done with the learners so that their needs are address. The basic ingredients of planning are establishing goals, selecting techniques and materials to achieve these goals, and evaluation to see if the goals have been met.

5. Enthusiastic: Enthusiasm is catching. If one is deeply interested in a group of ideas, a set of facts, or a type of work, one is also more likely to get others interested. Enthusiasm is the natural celebration of the joy of learning a bit of knowledge or a new skill. Students love enthusiastic teachers and andragogues, too; and, will as a result get 'steamed up' about learning. It affords them the opportunity to explore new ideas and expand themselves in new directions with the support of a knowledgeable and exciting andragogue.

Other qualities of an effective andragogue would certainly include: Desire to instruct, a genuine sense of humor, being flexible, tact, patience, using a variety of learning techniques and courtesy. The reader may even be able to add other techniques to this list.

\section{Who is Competent to Design, Implement, and Facilitate the Curriculum of Andragogy?}

Biao (2005) addresses the andragogical issue of a tendency on the part of other educators (and even other adult educators not inclined to consider the validity of andragogy as being part of adult education) to think that any educator can teach, administer, manage, research, etc., an andragogical program/curriculum, or course. One aspect of this he seeks to articulate is that in andragogy various appropriate terms are important to replace, drop, and put them in the place of the more general terms used in education. These replacement terms are: adult educational program replaces curriculum, learner replaces student, facilitator replaces teacher, and learning center or learning environment replace school. On a broader level, the what, why and how of adult education are related first to the survival needs of adult learners and secondly to their aesthetic needs. There are other aspects of this but the above terms serve to illustrate the point that andragogy programs and courses need to be staffed by people academically prepared and competent in andragogy.

Some may wonder why Henschke even included this question above. In his perspective and experience, there are those educators including adult educators who do not agree with this brand of andragogy, to which he quickly adds and supports that they have every right to their own point of view. Nonetheless, having been engaged in person during his doctoral program in andragogy with a facilitator (Malcolm S. Knowles) who 'practiced what he preached,' he bought into the importance of congruence between theory and practice, 'hookline-and-sinker.' Although many educators and even adult educators that consider it appropriate for anybody, even those who do not accept andragogy as an operational mode for them, as competent to design, implement and facilitate the curriculum of andragogy. This is not the brand of andragogy his is able to support. That kind of inconsistency between 'word' and 'deed' is troublesome to him, and indeed happens more frequently that he likes to imagine, since there are those who talk about and know the language of andragogy, but they do not practice andragogy the way they talk about it - their 'walk' and their 'talk' are not congruent. This may be described as being like many teachers (not andragogues) that he has been subjected to over the years; they basically are demonstrating the principle of 'do what I say, not what I do.' Suffice it to say that during the initial year of his first employed position in adult education 44 years ago, Henschke was required to participate in a program planning conference. The most striking part of that conference was a presentation on "The 
Forty-Seven Principles of Adult Learning," and the presenter violated every one of them while he was presenting them to the conference. A never to be forgotten experience, Henschke has consistently sought to make his 'walk' and 'talk' as an andragogical adult educator congruent, not incongruent. The following is offered to the reader for consideration about how she/he may wish to conduct adult education program[s].

\section{Questions to Be Addressed in Selecting Techniques for Facilitating an Andragogy Curriculum}

Having established that programs/curricula in andragogy (adult education) need to be facilitated by those prepared and competent in andragogy, a next step may be to consider how one goes about selecting techniques or methods for facilitating andragogical adult learning as it relates to any subject matter. Andragogical adult education curriculum is a process, and the subject matter content may be any one or more of numerous subjects or topics that adult learners may be required to learn for their lives, their work, as citizens in the community, or in world affairs.

While I am reflecting on reasons and the process for moving in the direction of facilitating any adult learning which includes the principles of andragogy in adult learning and practicing the research findings of our field, the major reason which became apparent is the belief that this is important enough to make the commitment to do. This is not a matter of how long it takes to refine the curriculum process in order to get past the "rough edge" stage and to be headed toward the "comfort zone" stage. The literature in andragogy is supportive, explanatory, suggestive, idea sparking and a help to follow through on the commitment. McLagan (1990) in Sustaining Change suggests that in changing any of our practices toward facilitating andragogy, we need to crack the genetic code and awaken organizations (and that means, we the professionals who are in them) to such a level they (we) can't go back to the ruts of our proceduralized, anesthetized, sleep - and in this situation it means, we can't go back to conducting any andragogical curriculums, programs or learning sessions without using adult learning techniques to actively and dynamically involve the participants.

It may be well for andragogues and, incidentally, an improvement for the andragogical field when professionals are preparing for and conducting presentations of any kind to ask and answer for themselves the following three questions as guidelines for the practice of selecting and using learning techniques: (1) How does the selection and use of a particular learning technique for this conference session fit into an andragogical understanding of the way adults learn or change (learning theory)? (2) What position does this learning technique hold in the context of learning objectives in this conference session (learning design)? (3) What immediate and observable learning needs does this adult learning technique meet at this time with these conference participants (specific relevance)? (Henschke, 1992, p. 64).

\section{A Facilitator's Process Plan in Andragogical Curriculum}

One of the strongest cases made for the importance of process in facilitating any andragogical learning is to consider a suggestion of Knowles (1980, pp. 319-320) regarding a facilitator's process plan that could be used especially with any andragogical curriculum. Questions that are important are provided for the opening session and for subsequent sessions.

At the opening session:

- How will you introduce yourself? How will you describe your perception of your role, your special resources and limitations, your availability for consultations, etc.?

- What procedures will you use to engage the participants in becoming acquainted 
with one another in terms of their work experience, resources, and interests.

- What other procedures will you use to establish a climate of mutual respect, collaborativeness, informality, security, warmth of relationship with you, supportiveness, etc.?

- How will you engage the participants in examining, clarifying, and influencing the objectives of the program?

- How will you acquaint the students with your plan of work for the program and their responsibilities in it?

- How will you help them prepare to carry the responsibilities you expect of them?

- How will you acquaint the participants with the resources (material and human) available to them for accomplishing their learning objectives?

- What learning activities will you suggest the participants engage in between the first and second sessions of the program?

- What physical arrangement of your meeting room do you prefer to facilitate interaction among the participants and between them and you? (Indicate which session when appropriate). (Knowles, 1980; adapted from pp. 319-320.)

In subsequent sessions:

- How will you engage the participants in diagnosing their individual and collective needs and interests regarding the content of the program?

- How will you engage the participants in formulating learning objectives based on their diagnosed needs and interests?

- What specific learning strategies (methods, techniques, devices, materials, etc.) do you propose using in this program?

- How will the participants be involved in selecting and participating in these strategies?
- What procedures and tools will you use for helping participants assess their progress toward their objectives?

- What procedures and tools will you use for evaluating learning outcomes at the end of the program?

- If appropriate, how will evaluation of their performance be arrived at?

- What procedures and tools will you use for getting feedback from the participants periodically and at the end regarding the quality of this learning experience?

- What content do you expect to be acquired through this program (including knowledge, understanding, skills, attitudes, and values)? (Knowles, 1980; adapted from pp. 319-320.)

A quick observation on these above questions may yield a startling fact: there are 18 questions included with 17 of them focusing on the process that the andragogical facilitator may use. There is only one of them focusing on the subject matter content. This may see inordinately weighted in favor of the process. Nevertheless, it emphasizes the worth of considering the extreme importance of facilitating the process of learning andragogically.

\section{A Living Lecture in Andragogy}

A largely untapped resource for andragogical learning and improving our individual lives and as a society is the large meeting - sized from 10 to thousands. Many people use these meetings to have just one person to speak and have everyone else listen. There are ways to take advantage of these kinds of opportunities to help many people learn and be actively involved in the process. One of the regular happenings with which facilitators of andragogy are faced, is events that include large (and not so large) group meetings. Henschke has used this technique in group meetings to great advantage since 1971 up to present while writing this article. This is a way to enhance interactions 
with Listening Teams: Clarification, Rebuttal, Elaboration, Practical Application. Before a presentation the audience can be asked to serve as "listening teams" according to the section of the room they are sitting in---one section to listen to the presentation for points requiring clarification (the clarification team), another for points with which they disagree (the rebuttal team), another for points they wish to have elaborated on (the elaboration team), and a fourth for problems of practical application they wish the speaker to address (the application team). After the presentation the teams are asked to "buzz" in groups of four or five to pool their thinking about the points they want raised, following which one member of each group gives a summary of its deliberations and the speaker responds to each item in turn until time runs out or all items are discussed. (Knowles, 1970; adapted from p. 154). He has used this process beneficially with more than 25 groups from four people to 275 people in Brazil, USA, Peoples' Republic of China, Thailand, Australia, Italy, South Africa, Germany, West African Republic of Mali, and Taiwan. He has also used it with large groups of 100 in International Video Conferences. It has always been received well and helps to actively involve the participants in learning with large and smaller groups (Henschke, 2011c).

\section{A Brazilian Engineering Professor, UFPA}

Using some of these processes listed above with a Brazilian Engineering Professor in the College of Engineering at the Federal University of Para (UFPA), Brazil, brought an interesting observation. He had shared that he was having difficulty with getting some of his students to understand engineering concepts. They just did not seem to get it, and he didn't feel that he was connecting with them. As we used the adult learning processes, we were trying to make a connection with the characteristics of the learners, and then would suggest (and demonstrate the use of) techniques that would constructively respond to each one of the characteristics. As examples, we used the following; for the characteristic of 'immediate concerns,' techniques suggested were to use realistic problems, adult-oriented materials, and concrete situations. For the characteristic of 'low self-concept', techniques suggested were to respect learners for what they respect in themselves, involve them in planning and decision-making for the curricula, and tap their experiences. For the characteristic of 'alienation-loss of control,' techniques suggested were to enhance attitudes about their ability to learn, orient learners to be active and seek community resources rather than focus on events, cite examples in which awakened human potential changes one's life drastically (Henschke, 1989). As we went through these suggestions, one at a time, finally this engineering professor exclaimed,

Now I get it, I know what I have been doing wrong with my students. I know why I have not connected with them and they don't understand. 1 now know what I need to do that will help them understand the engineering concepts. I have only been focusing on the content, and I need to focus on them and engage with them so that they can process the concepts through their minds.

\section{Various Approaches and Different Sides to Self-Directed Learning in Andragogy}

From Knowles $(1970,1980)$ comes the suggestion that it is possible for andragogy to be somewhat of a comprehensive theoretical umbrella concept for learning, growth, development, action and impetus for moving a nation and the worldwide society constructively forward. He also asserts that self-directed learning (SDL) is somewhat akin to andragogy. Moreover, he perceives SDL as perhaps the major way that andragogy may be implemented for the advancement of the world society. Some may contest this, but I will provide 
Table 1. Basic characteristics of low-level adult learners and andragogical techniques for helping them learn

\begin{tabular}{|c|c|}
\hline $\begin{array}{l}\text { Characteristics } \\
\text { Immediate Concerns }\end{array}$ & $\begin{array}{c}\text { Andragogical Techniques } \\
\text { Use realistic problems, adult-oriented material, and concrete situations. }\end{array}$ \\
\hline Low Self-Concept & $\begin{array}{l}\text { Respect the learner for what he respects in himself; involve him in planning and decision-making } \\
\text { for the curricula; tap his experiences. }\end{array}$ \\
\hline Different Value Systems & $\begin{array}{l}\text { Relate education to life and direct plans of work to the coping skills of the learner; encourage open } \\
\text { discussions around the value shifts from youth into aging; make no moral judgments as to what is } \\
\text { good or bad. }\end{array}$ \\
\hline Use of Defense Mechanisms & $\begin{array}{l}\text { Allay excuses given by the frustrated without attacking them; emphasize importance of goal- } \\
\text { seeking and of becoming something better (constructive behavior); accept any patterns of self- } \\
\text { protection against internal as well as external threats. }\end{array}$ \\
\hline $\begin{array}{l}\text { Sensitivity to Nonverbal } \\
\text { Communication }\end{array}$ & $\begin{array}{l}\text { Be alert for clues of what is said and what is not said but felt; in responding, guard against } \\
\text { negative nonverbal responses in voice, gestures, or facial expressions. }\end{array}$ \\
\hline $\begin{array}{l}\text { Alienation (feeling of helplessness } \\
\text { over control of events) }\end{array}$ & $\begin{array}{l}\text { Enhance the learners' attitudes about their ability to learn; orient learners to be active and to } \\
\text { seek out resources in their community; cite examples in which human potential, once awakened, } \\
\text { changed one's life drastically. }\end{array}$ \\
\hline $\begin{array}{l}\text { Reticence and lack of Self- } \\
\text { Confidence }\end{array}$ & $\begin{array}{l}\text { Help learners to experience success and security by giving small tasks before proceeding into } \\
\text { more demanding activities; present well-planned and meaningful lessons; begin with familiar and } \\
\text { concrete problems; add humor to every session. }\end{array}$ \\
\hline $\begin{array}{l}\text { Hostility and Anxiety Toward } \\
\text { Authority }\end{array}$ & $\begin{array}{l}\text { Project yourself as a friend or guide with genuine honesty and a warm regard for each person; } \\
\text { dress conservatively; allow controversy in group discussion; speak in conversational tone. }\end{array}$ \\
\hline Fear of School, Failure and Change & $\begin{array}{l}\text { Assure entire group that choice of seating, responses, and homework are to be voluntary; teach } \\
\text { good study habits; encourage interaction; set a warm, informal, relaxed atmosphere; constantly } \\
\text { reassure learners in their small successes. }\end{array}$ \\
\hline $\begin{array}{l}\text { Limitations from Deprived Home } \\
\text { Life }\end{array}$ & $\begin{array}{l}\text { Find ways to remedy the physical and emotional handicaps resulting from limitations in } \\
\text { environment; provide a quiet, comfortable place for study; provide well-stocked supplementary } \\
\text { aids; encourage use of the library, agencies, and/or learning center. }\end{array}$ \\
\hline Cultural Exclusion & $\begin{array}{l}\text { Provide a link between learners and sources of pleasure, learning, and cultural enrichment open } \\
\text { to them; post schedules of community activities or review with learners the weekly events in } \\
\text { local papers; schedule field trips to lectures, libraries for films or demonstrations, or public court } \\
\text { hearings; invite a cooperative extension agent to give a demonstration relating to some home need } \\
\text { expressed in planning sessions. }\end{array}$ \\
\hline
\end{tabular}

some suggestions on how SDL may be considered for this very effort. First, one may start experimenting with the concept, even if she/he has no awareness of having previously self-directed in learning. This is a reflective experience. Second, after one has an initial experience of becoming aware of his/her own SDL, taking responsibility for one's own learning may be a next step. Third, one my want to concentrate on advancing her/his level of skill in SDL. A natural fourth step may be in becoming a facilitator of SDL in others, even in an informal setting. So, following are some examples to follow through on these steps in SDL.
1. Reflections on my Self-Directed Learning Experience (for one who thinks he/she is not)

a. Recall your largest, most intentional change in the last two years. Career, job training or education Self-Insight \& Self-Perception Body and Physical Health Emotions \& Human Relations Basic Skills for Future Situations Where you live Retirement Job

Enjoyable Activities 
Methods for Managing Time \& Life Concerns: Like in Family Life Spiritual Growth Personal Finances Understanding the Meaning of Life Home Furnishing \& Maintenance Social and Political Actiom Volunteer Activities Traveling (other)

b. As a way to select your top choice, place a rating of \# 1 for your top choice and \# 19 for your lowest choice. Use each number only once.

c. Who chose, planned, or implemented the change? People or book?

d. What resources stimulated the change?

e. How did you go about making the change?

f. Did you have a vision of what you would be doing when the project was complete? If yes, describe the vision.

g. Were there any unintentional or incidental changes that occurred accompanying the major change? If yes, describe them?

2. Different sides of self-directed learning is a process in which learners (students) take responsibility for their own learning, including diagnosing needs, developing objectives, designing learning experiences, finding resources, and evaluating learning outcomes.

a. On the one hand, characteristics of highly self-directed learners are:

Self-Confident

Inner-Directed

Reflective

Achievement Motivated

Accommodating

Creative, Holistic Thinker

Not Dogmatic

Which ones characterize you? Rate yourself on each on a scale of 1 (lowest) to 10 (highest). b. On the other hand, skills of individuals with high levels of self-direction are: Strong Goal Setter Good Decision Maker Accurate Observer Effective Listener High Reading Level.

How do your skills match these? Rate yourself on each on a scale of 1 (lowest) to 10 (highest).

c. The other side of self-directed learning is being a facilitator of learning — the kind of person who can help make self-directed learning happen in others. Facilitators of selfdirected learning, must know the following:

How adults acquire and use skills, knowledge, and attitudes,

How to apply different learning styles,

How to help individuals, and groups with personal needs, ethical issues, and problems,

How to help people establish personal and work-related goals,

How to offer feedback on a timely basis, How to observe groups unobtrusively and gain information and insight,

How to influence people to accomplish tasks and learn continuously,

How to manage conflict in work settings at the individual, group, and organizational levels

How to negotiate so that all parties win, How social systems at work influence productivity and quality,

How to communicate often and effectively in visual, oral, and written formats,

How to gather information and stimulate insight in individuals, work teams, and groups through the use of interviews and other techniques, 
How to use quantitative and qualitative methods to analyze skill and learning needs,

How to establish positive, workable 'relationships across a broad spectrum of people and groups,'

How to gain others' short- and long-term commitment to learning,

How to build cohesive, viable work teams and self-directed groups,

How to model self-esteem and foster self-esteem in others,

How to apply workplace-learning and performance-improvement theories,

How to develop and maintain learning environments that are conducive to creativity,

How to accept uncertainty and get others to accept uncertainty,

How to use positive interpersonal skills in various work settings,

How to show concern and empathy for diverse learners and workers,

How to use listening skills in different work settings,

How to understand nonverbal communication among diverse individuals and groups,

How to coach individuals and groups,

How to give appropriate verbal and behavioral responses in stressful work situations, and,

How to help reduce learners' stress in different work settings.

How do you score on these? Rate yourself on each on a scale of $\mathbf{1}$ (lowest) to $\mathbf{1 0}$ (highest).

\section{Learning Styles that Will Help Enhance the Andragogical Curriculua}

One aspect of the Andragogical Curriculum may include Learning styles. One may ask, what are they? People are unique and learn in four (4) dif- ferent ways, contrary to the long standing idea that everyone learns the same way. A learning style is made up of two (2) major component parts; Perceiving how we take in information; and, Processing — how we make that information a part of ourselves (Kolb, 1974). First, Innovative Learners perceive information by sensing and feeling concrete reality; but, they process information by watching what is happening and reflecting on it. Second, Analytic Learners perceive information by abstract reasoning and thinking; but they process information by watching what is happening and reflecting on it. Third, Common Sense Learners perceive information by abstract reasoning and thinking; but they process information by actively experimenting with it through jumping in and trying it. And fourth, Dynamic Learners perceive information by sensing and feeling concrete reality; but, they process information by actively experimenting with it through jumping in and trying it. One may access the Kolb Learning Style Inventory (LSI) through the amazon.com Website. Although completing the LSI will help one find their dominant learning style, the major value of the LSI is that it may help one become aware of the importance of completing each of the four aspects of one's learning cycle. Kolb (1974) seeks to make clear that if one does not work through each of the four quadrants, one's learning is incomplete. Completing and understanding the learning cycle is an important aspect of andragogical learning. Another item that may have to do with curriculum in andragogy is related to brain research and learning.

\section{Brain Research and Emotional Intelligence in Andragogical Learning}

One of the recent trends in brain research and learning takes us beyond the description of the left brain being cognitive, technical or linear, and the right brain being emotional, creative or global. The trend now is toward explaining how emotional intelligence outweighs cognitive ability 
and technical skills as a contributor to constructive success of andragogical curricula in the workplace or any other context (Restak, 1997).

On the emotional intelligence framework, Social Competence and Personal Competence are the two major components. Social Competence determines how we handle relationships, and is comprised of Empathy - awareness of others' feelings, needs, and concerns; and Social Skills_ adeptness at inducing desirable responses in others. Personal Competence -- determines how we manage ourselves, and is comprised of Self-Awareness - knowing one's internal states, preferences, resources, and intuitions; SelfRegulation - managing one's internal states, impulses, and resources; and Motivation- emotional tendencies that guide or facilitate reaching goals (Goleman, 2005).

Aspects of the brain and emotions act to expand other dimensions of human learning and one's life in addition to the intellect, which is consentrated on in school. There are some (Restak, 1997; Goleman, 2005) who assert that these aspects have been tested and found to make more contribution to solving problems that heretofore we have sought with mixed results to depend mostly on logic and intellect.

\section{Application of Andragogical Learning to Various Parts of Life}

If the trend of lifelong education which is also andragogical is to succeed as the heartbeat of the twenty-first $\left(21^{\text {st }}\right)$ century, it must be organized around six (6) types of learning and applied as the pillars of knowledge interacting together throughout a person's life. This may be undertaken with self-initiation and energetic forward thinking, as follows:

- Learning to Know: Acquiring the instruments of understanding.

- $\quad$ Learning to Do: Ability to do a job of work and act creatively on one's environment.
- Learning to Live Together: To participate and co-operate with other people in all human activities.

- $\quad$ Learning to Be: Enabled to determine for themselves what they believe they should do in the different circumstances of life.

- $\quad$ Learning to Change: A shift of the mind from what was to what is possible.

- $\quad$ Learning for Sustainability: Developing a capacity into strength, forthrightness and maintenance.

All of this application will reveal the treasure within the learner and grows from each person selecting out of their learning experience one or more ideas they would like to try out in their back-home situations. Then they may identify the steps they would take in applying the idea(s), and consider any obstacles or resistances they anticipate encountering in putting the idea(s) into effect. Lastly, strategies may be suggested which will help in dealing with and overcoming the obstacles and resistances for bringing about change. Application of learning ultimately culminates with learning and worthy performance going hand-in-hand as being two sides of the same coin (Delors, 1998).

\section{Suggested Objectives in Improving Andragogical Curricula}

There are different points-of-view regarding what objectives need to be included in improving andragogical curricula. Many educators, some adult educators, and even those few that call themselves andragogues, but have little or no understanding of andragogy, limit themselves and their work to knowledge and skills objectives. Some will add to this an objective on attitudes. However, over the years Henschke has been practicing andragogy in curricula, there are six categories of objectives which have been included. These make for a more comprehensive development of the person and the communities where one lives. These are listed and a definition for each is provided: 
1. Knowledge: Generalizations about experience; internalization of information.

2. Understanding: Application of information and generalizations.

3. Skills: Incorporation of new ways of performing through practice.

4. Attitudes: Adoption of new feelings through experiencing greater success with them than with old.

5. Values: The adoption and priority arrangement of beliefs.

6. Interests: Satisfying exposure to new activities.

\section{Human Indignities and How to Overcome Them with an Andragogical Approach}

Perhaps the worst human indignity came from the what was known as "America's bloodiest prison" (Cymbala, 2008, p. 80), where most inmates had no-parole sentences, where they would spend their remaining days in a single-story cinder block building on a flat, humid landscape. One's life may be cut short by a knife's flash, a rifle's blast, or a cigarette lighter's flame, since inmates were encouraged by being given money to get rid of anyone a guard didn't like. The funeral of one inmate concluded a rainy afternoon when the soggy bottom fell out of the cardboard casket (the standard that was used for burials to save the prison money) just as it was being lifted into place at the open grave. As the inmate mourners gasped at the body tumbling into the hole, the guard told the workmen to dump the remainder of the casket onto the body and shovel the dirt to rapidly cover up the mess.

This prison had a well-documented history of abuse and brutality. However, a change of culture came and transformed this horrible place. Following is a passage directly from Cymbala. $\mathrm{He}$ (2008) writes:
So what happened to change the culture of this dreadful place?

A short, silver-haired warden named Burl Cain arrived in early 1995 . His predecessor had told him he would last no more than five years. Another person claimed there were demons over the place. Cain's response? "I'm going to run them off, with God's help."

Burl Cain established from the first day that he would treat inmates with respect. He shocked some by sitting down to eat with them in the dining hall. There he was appalled at the poor quality of food and quickly ordered the kitchen staff to do better. It did not matter to him whether the prisoners were white, like him, or of some other race. He became a walking demonstration of the Golden Rule: "Do to others what you would have them do to you" (Matt, 7:12). He put himself in the place of one who had made a big mistake in life and been sentenced to Angola. How would he want to be treated? As a human being, or a dangerous animal?

Cain began training his staff to stop the insults and name-calling. He opened up new opportunities for study and achievement. He threw his full efforts behind the annual rodeo, where inmates got to perform for the visiting public and also to sell crafts made throughout the year. An arena seating 9,000 was built (with private money); each October it is packed out for the festivities.

But this warden is no soft touch. He knows how to crack down hard - but with fairness-on infractions. He has proved to all concerned that it's not wise to challenge him.

He calls his strategy "moral rehabilitation," by which he means learning to live peacefully and productively in a prison community. "I realized I could teach them to read and write, could help them learn skills and a trade," Cain says, "but without moral rehabilitation, I would only be creating a smarter criminal." That is why his emphasis on spiritual growth has been given such priority. 
Angola is a place where increasing numbers of prisoners want to do the right thing before God.

As a result, you can walk around the institution and hardly believe you are in a penitentiary. Large numbers of men live not in cells but in open dormitories. They greet their chief with "How ya doin,' Warden Cain? Praise the Lord!" They know him as a man who looks for ways to say yes to their requests, rather than always saying no.

The average sentence length at Angola is still eighty-eight years, given this population of murderers, rapists, and repeat violent felons. The tough Louisiana laws and policies are still as tight as ever against granting parole, even to well-behaved prisoners; it seldom happens. Yet hope is alive in this place. The annual capture of contraband weapons each year is down from 800 in the past to fewer than 50 last year.

When a man on death row has finished all the legal procedures and comes to the day of execution, he is accompanied every step of the way by Burl Cain. The warden attends the prisoner's final meal and eats with him. He spends hours answering the convicted man's questions, explaining in detail how lethal injection works, going over every step of the coming hours. He then prays with the inmate.

On the way to the death chamber is a reception area with two large murals painted by prisoners. One depicts Elijah in a fiery chariot rising to heaven; the other shows Daniel standing fearlessly in the lion's den. When the fateful hour comes, Burl Cain is present at the gurney. He takes the man's hand, looks into his eyes, and gently offers words of comfort. Only then does he do what the state requires of him: he nods to the executioner to start the flow of toxic drugs into the man's veins.

A few minutes later, Cain stands before the waiting media to make his trademark announcement: "We have now sent [name] to his final judgment." He deliberately avoids using the words execution or death.

For any funeral on penitentiary grounds, the scene could not be more opposite from the old days of cardboard caskets. The prison's woodworking shop builds exquisite oak coffins, hand-polished to perfection. (They are so impressive that Samaritan's Purse president Franklin Graham bought two of them for the use of his famous parents, Billy and Ruth Graham.) On funeral day, the casket is reverently loaded onto a black antique hearse wagon with glass sides, pulled by two massive Percheron horses. The inmate driver sits high above, wearing a tuxedo with a black top hat.

The procession moves slowly toward the prison's Point Lookout Cemetery. There, whitewashed cement crosses mark each grave. To the very end, those whom society has locked away are treated with dignity and respect. As one of his assistants puts it, "It's one thing to say that inmates are human. It's another to treat them that way. The warden has taught me how to do that." (pp. 82-84)

This seems to bring us full circle in which we become more aware of the positive possibilities of improving our individual lives as well as the lives of other. It is what one could label as coming about by by means of a successful andragogical approach. This also may help to leave the world a better place for future generations.

\section{FUTURE RESEARCH DIRECTIONS}

Possibly there are many areas that would be useful to be research directions. Some suggestions follow. They are: Brain research, learning styles, andragogy history, andragogy philosophy, themes of andragogy, categories and kinds of objectives, clarity on the full range of what andragogy encompasses. This also may include connection of the economy around the world and the andragogy, pedagogy, and all other 'gogy' debates. Certainly, any reader of this would have cogent suggestions of future research and probably has some current research areas upon which future research may be beneficially based. Rachal (2002) poses an empirical research structure for research in andragogy. A number of researchers are beginning to follow this path. Vodde (2008) conducted a solid study 
based on Rachal's model and applied this to the preparation of police, finding they are better prepared by andragogy that pedagogy. Others are beginning to apply this model to other disciplines, and we will be benefited if more initiate actions around this path. Research into the influence of andragogy on the economy is quite promising for yielding a good harvest of fruit, given the shakey condition of the worldwide economy.

\section{CONCLUSION}

Implementing a prepared plan for andragogical curriculum will help in the equipping nonexperienced and veteran teachers of adults is the final conclusion of conducting a program. This is a most crucial part of the process. It seems that this step cannot be directly taught. It is not readily articulated, openly expressed or stated. It is unspecifiable. It may be called the tacit dimension of practical knowledge. This is like an integration of the explicit and objective subject matter knowledge of one's practice into the personal constructions and performances of one's work. It is the developing of an intuition of what needs to be done in this specific situation to take the next step which will carry the learning forward. It is as though attitude is of utmost importance; attitude toward one's self, toward the great potential of adults as learners, the opportunity of being involved in turning the light on in their eyes:

- An attitude of being open to ideas that are different from those in the design.

- An attitude of caring and showing it.

- An attitude of treating adults as individual adults who are unique.

- An attitude of supportiveness toward learners.

- An attitude of considering the learning process as important.
Implementation of an andragogical curriculum is the creation of a climate which nurtures the seeds of adult learning into a glorious flower that flourishes. It is practical intelligence, practical reasoning, practice of the art of facilitating the learning of adults which is different from talking about the rules of adult education. It is not just talking about adult education of andragogy. It is about doing andragogical adult education and doing it well. This comes from following our inner sense, honing the skill, and practice, practice, practice, until it is refined like a costly and precious gem. It is excellence personified.

It is a fact that we all know more about excellence than we put into practice. However, Henschke wishes to accept the challenge himself and invite others to join him in allowing these andragogical ideas and concepts to transform all of us into more excellent andragogues. These concepts -- adult and child learning, self-directed learning, learning styles, brain research and learning, application of learning, building blocks of adult learning experiences, and modeling adult learning -- may have a huge impact upon us. Then, we will not only be talking about andragogical curriculum, but also we will be doing it and doing it better than we ever have before now; thus, transforming ourselves into successful andragogues. It will be like putting together the warp and the woof of an exquisitely beautiful cloth weaving. We will be paying tribute to those who have given so much of themselves in andragogy to our benefit. We will also be refining costly and precious gems - adult learners, who are becoming increasingly self-directed and are budding and flowering andragogues. It will come together like the warp and the woof of an exquisitely beautiful cloth weaving. Thus, we will create a better climate with the adult learners for nurturing their seeds of andragogical learning into a glorious flower that flourishes and contributes to the communities, nations and world in which we live. 
All of this implementing the andragogical curriculum is like combining in one package what has been said thus far. Then, each person's shaping these concepts and practices by her/his own uniqueness, while pulling it all together and following the innermost connection of all the key terms in this paper, within each one's own being for moving forward with the constituencies each of us serves: Taking our underlying being, with the most vibrant means at our disposal in a way that will make up a format with dynamic methods and techniques to instruct and facilitate the kind of learning, growth, development, and maturing the will be bringing out the best in individuals, nations and societies around the globe.

\section{REFERENCES}

Biao, I. (2005). Pedagogical and andragogical warfare and the psycho-sociology of andragogizing in Nigeria. Lagos, Nigeria: University of Lagos.

Boone, E. J.(1985). Developing programs in adult education. Englewood Cliffs, NJ: Prentice-Hall.

Cymbala, J. (2008). You were made for more. Grand Rapids, MI: Zondervan.

Delors, J. (1998). Learning: The treasure within. Paris, France: UNESCO Publications.

Devlin, J. (1939). Webster's twentieth-century dictionary of the English dictionary: Being the unabridged dictionary by Noah Webster. New York, NY: Publishers Guild.

Goleman, D. (2005). Emotional intelligence: Why it can matter more than IQ. New York, NY: Harper and Row.

Henschke, J. (2011a). Considerations regarding the future of andragogy. Adult Learning, 22(1), 34-37.
Henschke, J. A. (1989a). Identifying appropriate adult educator practices: Beliefs, feelings and behaviors. In Proceedings of the Eighth Annual Midwest Research-to-Practice Conference in Adult, Continuing and Community Education. St. Louis, MO: University of Missouri.

Henschke, J. A. (1989b). The adult learner. St. Louis, MO: University of Missouri.

Henschke, J. A. (1992). Using adult learning techniques in adult education conferences. In Proceedings of the Eleventh Annual Midwest Research-to-Practice Conference in Adult, Continuing and Community Education. Manhattan, KS: Kansas State University.

Henschke, J. A. (1998). Modeling the preparation of adult educators. Adult Learning, 9(3), 11-14.

Henschke, J. A. (2009). Movement toward staying ahead of the curve in developing and managing human capital. In W. Wang, \& K. P. King (Eds.), Human performance models in the global context (pp. 1-27). Charlotte, NC: Information Age Publishing.

Henschke, J. A. (2011b). Building blocks for the adult learning experience. In Proceedings of the 2011 Midwest Research-to-Practice Conference in Adult, Continuing, Extension, and Community Education. St. Charles, MO: Lindenwood University.

Henschke, J. A. (2011c). A living lecture for lifelong learning. In Proceedings of the 2011 Midwest Research-to-Practice Conference in Adult, Continuing, Extension, and Community Education. St. Charles, MO: Lindenwood University.

Henschke, J. A. (2013). A 2013 update of research in andragogy has revealed some new dimensions and another era as we look toward andragogy's future. Paper presented at the Dialogues of Andragogy Special Interest Group (SIG), during the 2013 Commission of Professors of Adult Education (CPAE) Conference. Lexington, KY. 
Henschke, J. A. (1999, 2013), Adult education: Some global trends. In Proceedings of the First Scholarship Meeting of the Academic. Beijing, China: Academic Press.

Jarvis, P. (1990). An international dictionary of adult and continuing education. London, UK: Routledge.

Knowles, M. S. (1970). The modern practice of adult education: Andragogy vs. pedagogy. New York, NY: Association Press.

Knowles, M. S. (1980). The modern practice of adult education: From pedagogy to andragogy (Revised and Updated). New York, NY: The Adult Education Company.

Kolb, D. (1964). Experiential learning. Upper Saddle River, NJ: Prentice-Hall.

Lubin, M. M. (2013). Coaching the adult learner: A conceptual framework for engaging the principles and processes of andragogyfor best practices in coaching. (Unpublished doctoral dissertation). Virginia Tech University, Falls Church, VA.

McLagan, P. (1990). Sustaining change. Retrieved from http://mclaganint.com/

McLagan, P., \& Nel, C. (1995). The age of participation: New governance for the Workplace and the world. San Francisco, CA: Berrett-Koehler Publishers.

Moehl, P. (2011, July). Exploring the relationship between Myers-Briggs type and instructional perspectives among college faculty across academic disciplines. (Unpublished Doctoral Dissertation). University of Missouri-St. Louis, St. Louis, MO.

Rachal, J. R. (2002). Andragogy's detectives: A critique of the present and a proposal for the future. Adult Education Quarterly, 22(3), 210-227. doi:10.1177/0741713602052003004
Restak, R. (1997). Older and wiser: How to maintain peak mentality as long as you live. New York, NY: Mass Market Paperback.

Stanton, C. (2005). A construct validity assessment of the instructional perspectives inventory. (Unpublished Doctoral Dissertation). University of Missouri-St. Louis, St. Louis, MO.

Titmus, C. J. (Ed.). (1989). Lifelong education for adults: An international handbook. Oxford, UK: Pergamon Press.

Vatcharasirisook, V. (2011). Organizational learning and employee retention: A focused study examining the role of relationships between supervisors and subordinates. (Unpublished Doctoral Dissertation). University of Missouri, St. Louis, MO.

Vodde, R. F. (2008). The efficacy of an andragogical instructional methodology in basic police training and education. (Unpublished Doctoral Dissertation). Department of Criminology, University of Leicester, Leicester, UK.

\section{KEY TERMS AND DEFINITIONS}

Being: Getting up and living, come to life, spirited, come through.

Facilitate: Make easy, make easier, facilitate, ease, assist, aid, help; help on or along, smooth, grease, oil, lubricate, iron out, pave the way, smooth the way, prepare the way, grease the way, soap the way, grease the wheels; clear, unclog, unblock, unjam, unbar, free, loose, open up, clear the ground, clear the way; make way for, not stand in the way of, make all clear for, open the door to, bridge the gap; allow, permit, enable, make possible; promote, advance, further, forward, hasten, speed, accelerate, expedite, pioneer, give scope; make clear, explain, clarify, simplify, gloss, popularize, vulgarize, interpret, translate. 
Format: Architecture, shape, configuration, mold, composition, fashion, morphology, composition.

Instruct: Explain, show how, make clear, illuminate, exemplify, delegate, particularize, illustrate, give instances.

Make Up: Embody, compose, put together, assemble, build, crafting.

Means: Manner, wherewithal, capacity, ability, know-how, process, tools of the trade, steps, knack.
Method: Formula, proposition, natural law, rule of thumb.

Technique: Style, design, pattern, manner, approach, tome, quality, fashion, characteristic.

Underlying: Internal, innermost, central, core, inside, inmost, center.

Vibrant: Robust, energetic, dynamic, intense, vital, keen, brisk.

Way: Form, system, modus operandi, mode, manner, working arrangement, means. 